\title{
Acknowledgement to Reviewers of Data in 2016
}

\author{
Data Editorial Office
}

Published: 11 January 2017

MDPI AG, St. Alban-Anlage 66, 4052 Basel, Switzerland; data@mdpi.com

The editors of Data would like to express their sincere gratitude to the following reviewers for assessing manuscripts in 2016.

We greatly appreciate the contribution of expert reviewers, which is crucial to the journal's editorial process. We aim to recognize reviewer contributions through several mechanisms, of which the annual publication of reviewer names is one. Reviewers receive a voucher entitling them to a discount on their next MDPI publication and can download a certificate of recognition directly from our submission system. Additionally, reviewers can sign up to the service Publons (https://publons.com) to receive recognition. Of course, in these initiatives we are careful not to compromise reviewer confidentiality. Many reviewers see their work as a voluntary and often unseen part of their role as researchers. We are grateful to the time reviewers donate to our journals and the contribution they make.

If you are interested in becoming a reviewer for Data, see the link at the bottom of the webpage http://www.mdpi.com/reviewers.

The following reviewed for Data in 2016:

Abreu-Harbich, Loyde V. Aguillo, Isidro F.

Alface, Patrice Rondao

Ali, Ahmed Loai

Araújo, Duarte

Armillotta, Antonio

Barajas, Karla Caballero

Biederman, Lori A.

Cadeddu, Maria

Callaghan, Sarah

Castillo, Gabriel

Cerdá, Artemio

Chorbev, Ivan

Clemente, Filipe Manuel

Coppo, Peter

Dereeper, Alexis

Engemann Jensen, Kristine

Fonseca Escudero, David

Gallotti, Riccardo

Garcia-Santos, Vicente

Healey, Nathan C.

Helbich, Marco

Hilgard, Joseph

Hollmann, Rainer

Horvath, Dragos

Hsu, Chun-Nan
Hunter, Elizabeth A.

Ignatius, Marcel

Isaac, Nick

Jeong, Yoo Kyung

Jiang, Jiepu

Juckes, Martin

Kerr, Grégoire

Khader, Shameer

Kim, Hyun

Kiyono, Ken

Lane, David

Li, Gang

Libbrecht, Maxwell W.

Liu, Zhichao

Lluis Gelpi, Josep

Luis Ortega, Jose

Martins, João P. A.

McArdle, Gavin

Melero, Remedios

Moghaddam, Saeed

Mukherjee, Satyam

Ngoy, Kikombo

Niclos, Raquel

Ntie-Kang, Fidele

Painho, Marco

Pappalardo, Luca
Pasluosta, Cristian

Pauchard, Aníbal

Pavlidou, E.

Poorazizi, Ebrahim

Rapaport, Franck

Re, Rebecca

Rinaldi, Fabio

Roberts, David L.

Sahajpal, Ritvik

Shi, Feng

Sismanidis, Panagiotis

Skoković, Dražen

Tang, Mei San

Tayyebi, Amin

Temko, Andriy

Thomas, Philippe

Trigo, Isabel

Turner, Benjamin

Turner, David D.

Valles, Manel

Varando, Gherardo

Vaughan, Greg

Verspoor, Karin

Vink, Gerko

Wang, Li

Wang, Xiaolong 
Wang, Xujiao

Willinsky, John

Wong, Ka-Chun

$\mathrm{Wu}$, Jiafeng
Yin, Jifu

Yu, Yunyue

Zhang, Zhilin (Zorro)

Zhao, Qinpei

Zhou, Xun

(c)

(C) 2017 by the authors; licensee MDPI, Basel, Switzerland. This article is an open access article distributed under the terms and conditions of the Creative Commons Attribution (CC-BY) license (http://creativecommons.org/licenses/by/4.0/). 